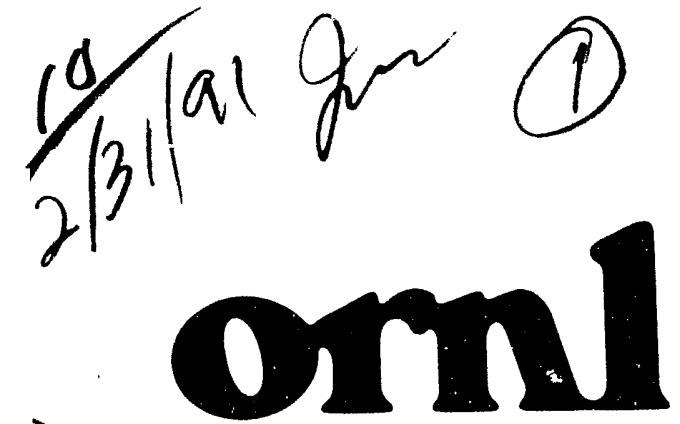

OAK RIDGE

NATIONAL

LABORATORY

MARTIN MARGETRA

\section{NA-NET \\ Numerical Analysis Net}

Jack Dongarra

Bill Rosener 
This report has been reproduced directly from the best available copy.

Available to DOE and DOE contractors from the Office of Scientific and Technical Information, P.O. Box 62. Oak Ridyu. TN 37831; prices available from (615) 576-8401. FTS 626-8401.

Available to the public from the National Technical Information Service, U.S. Department of Commerce. 5285 Port Royal Rd., Springfield, VA 22161.

NTIS price cocies-Printed Copy: AO7 Microfiche AO1

This report was prepared as an account of work sponsored by an agency of the United States Government. Neither the United States Government nor any agency thereof, nor any ci their employees, makes any warranty, express or implied, or assumes any legal liability or responsibility for the accuracv, completeness, or userulness of any informiation, appeaatus, product, or process disclosed, or represents that its use would not intringe privately owned rights. Reference herein to any specitic commercial product, process, or service by trade name, trademark. manufacturer, or otherwise. does not necessarily constitute or imply its encorsemeni, recommendation. of favoring by the United States Government or any agency thereof. The views and opinions of authors expressed herein do not necessarily state or reflect those of the United States Government or any agenov thereot 
Engineering Physics and Mathematics Division

Mathematical Sciences Section

\title{
NA-NET
}

NUMERICAL ANALYSIS NET

\author{
Jack Dongarra ${ }^{1}$ \\ Bill Rosener ${ }^{2}$
}

' Computer Science Department

University of Tennessee

Knoxville, TN 37996-1301

'Mathematical Sciences Section

Engineering Physics and Mathematics

P. O. Box 2008, Bldg. 6012

Oak Ridge National Laboratory

Oak Ridge, TN 37831-6367

2 Computer Science Department

University of Tennessee

Knoxville, TN 37996-13C1

DATE PUBLISHED - DECEMBER 1991

This work was supported in part by the National ficience Foundation under grant ASC-9103853, and in part by th: Applied Mathematical Sciences subprogram of the Office of Energy Research, U.S. Department of Energy.

Prepared by the

Oak Ridge National Laboratory

Oak Ridge, Tennessee 37831

managed by

Martin Marietta Energy Systems, Inc.

for the

U.S. DEPARTMENT OF ENERGY

under Contract No. DE-AC05-84OR21400 


\section{Contents}

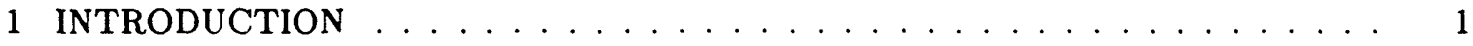

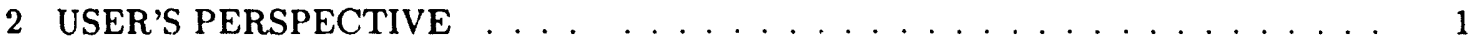

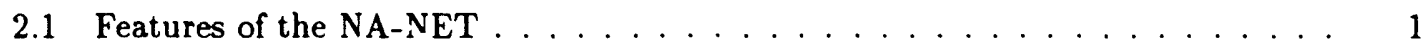

2.2 Features of the NA-NET White-pages $\ldots \ldots \ldots \ldots$

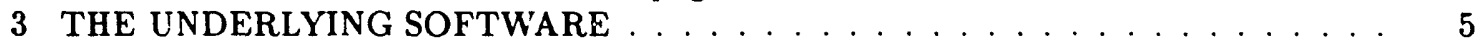

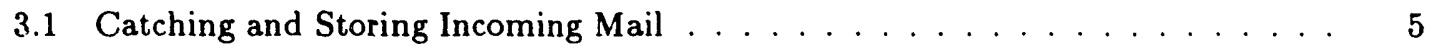

3.2 Processing the Incoming Mail . . . . . . . . . . . . . . . . . 6

3.3 Log and Debug Files . . . . . . . . . . . . . . . . . . . . . . . 10

3.4 Daily Usage Report . . . . . . . . . . . . . . . . . . . . . . . . . 10

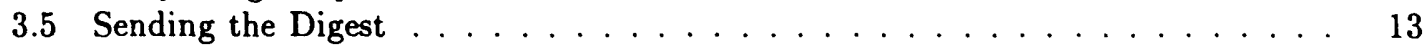

3.6 Removal of Bad Addresses . . . . . . . . . . . . . . . . . . . 13

3.7 NA-NET White-pages . . . . . . . . . . . . . . . . . . . 14

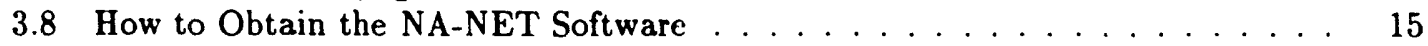

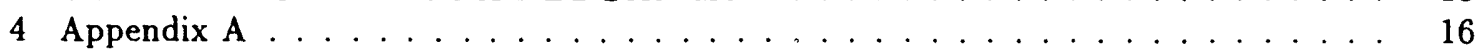

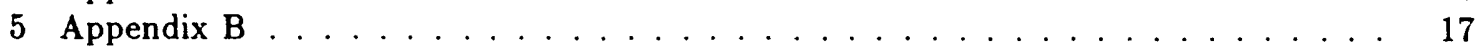

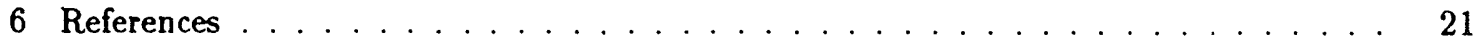


NA-NET

NUMERICAL ANALYSIS NET

Jack Dongarra

Bill Rosener

\begin{abstract}
This report describes a facility called NA-NET created to allow numerical analysts (na) an easy method of communicating with one another. The main advantage of the NA-NET is uniformity of addressing. All mail is addressed to the Internet host "na-net.ornl.gov" at Oak Ridge National Laboratory. Hence, members of the NA-NET do not need to remember complicated addresses or even where a member is currently located. As long as moving members change their e-mail address in the NA-NET everything works smoothly.

The NA-NET system is currently located at Oak Ridge National Laboratory. It is running on the same machine that serves netlib. Netlib is a separate facility that distributes mathematical software via electronic mail. For more information on netlib consult [3], or send the one-line message "send index" to netlib@ornl.gov. The following report describes the current NA-NET system from both a user's perspective and from an implementation perspective. Currently, there are over 2100 members in the NA-NET. An average of 110 mail messages pass through this facility daily.
\end{abstract}




\section{INTRODUCTION}

The NA-NET is a mail facility created to allow numerical analysts (na) an easy method of communicating with one ancther. The mair advantage of the NA-NET is uniformity of addressing. All mail is addressed to the Internet host "na-net.ornl.gov" at Oak Ridge National Laboratory. Hence, members of the NA-NET do not need to remember complicated addresses or even where a member is currently located. As long as moving members change their e-mail address in the NA-NET everything works smoothly.

The NA-NET originated at Stanford University by Gene Golub and Mark Kent [4], and is now under the direction of Jack Dongarra. Bill Rosener of the University of Tennessee has rewritten the software. Cleve Moler is the editor of the NA-NET News Digest.

The NA-NET system is currently located at Oak Ridge National Laboratory. It is running on the same machine that serves netlib. Netlib is a separate facility that distributes mathematical software via electronic mail. For more information on netlib consult [3], or send the one-line message "send index" to netlib@ornl.gov. The following report describes the current NA-NET system from both a user's perspective and also from an implementation perspective. Currently, there are over 2100 members in the NA-NET. An average of 110 mail messages pass through this facility daily.

\section{USER'S PERSPECTIVE}

\subsection{Features of the NA-NET}

Individual (unicast) messages - This is the most frequently used feature. Each member has a unique NA-NET name. This NA-NET name is usually the same as the members last name. However, if there is more than one member with the same last name then the first initial is usually preperded to their last name to form their NA-NET name. For example, if John Smith and Mark Smith both wanted to join the NA-NET then mail addressed to "na.jsmith@na-net.ornl.gov" would be used to send mail to John Smith and "na.msmith@na-net.ornl.gov" would be used to send mail to Mark Smith.

NA-NET News Digest - Any mail sent to "na.digest@na-net.ornl.gov" will be considered for distribution to all members of the NA-NET. About once a week the Editor of the NANET News Digest will go over the messages that have queued up, pick out the ones that are thought to be of general interest to the numerical analysis and mathematical software community, combine them in a News Digest format, and mail the Digest to everyone on the mailing list.

Joining the NA-NET - To join the NA-NET send mail to "na.join@na-net.ornl.gov". In the 
message body specify the following three fields.

\section{Lastname:}

Firstname:

E-mail:

The values can be specified in any order. The subject line of your message is ignored. If there is a member of NA-NET with the same last name, then a message will be sent back to you. If this happens try prepending your first initial to your last name. In this case the "key" that identifies you will not be your last name. See Appendix A for an example on how to join the NA-NET.

Removing membership - To remove your membership from the NA-NET send mail to "na.remove@na-net.ornl.gov". In the message body specify the following three fields.

Lastname:

Firstname:

Key:

The values can be specified in any order. Again the subject line of your message is ignored. A message will be sent to both the deleted address and the address making the request informing you that your name has been removed. See Appendix A for an example on how to remove your membership.

Changing e-mail address - To change your e-mail address send mail to "na.change@nanet.ornl.gov". In the message body specify the following four fields.

Lastname:

Firstname:

New-address:

Key:

The values can be specified in any order. Again the subject line of your message is ignored. A message will be sent to both the old-address as well as the new-address informing you that the change has taken place. See Anpendix A for an example on how to change your e-mail address.

Help - Questions and comments about the NA-NET should be addressed to: nanet@na-net.ornl.gov

Every effort will be made to have a person read all mail messages to this account. Mail sent to: na.help@na-net.ornl.gov 
will return a message describing both the NA-NET and the White-pages.

Current list of all members - Mail sent to the following address will result in a mail message being sent back to you containing all members of the NA-NET.

na.sendlist@na-net.ornl.gov

\subsection{Features of the NA-NET White-pages}

The "white-pages" is a directory service that has been recently added to the NANET. It allows users of the NA-NET to find out more information about other members. This facility is available to everyone. However, we would especially encourage members of the NANET to join. Like any directory service, it will only work if everybody takes a few moments to join, and then as necessary updates their entry. Below is a short description of the "white-pages" and how to use it.

1). Querying the White-pages database - To find out information about a person send mail to "na.whois@na-net.ornl.gov". In the message body or on the subject line specify their first name and last name, or just their last name. The order of first name and last name does not matter. See Appendix B for examples.

2). Joining the White-pages - To join the "white-pages" send mail to "na.join-wp@nanet.ornl.gov". In the message budy specify the two mandatory fields and as many of the optional fields as you want.

Mandatory

Last_name:

First_name:

Optional Fields

Middle_name:

Other_name:

Affiliation:

Office_address:

City_state_zip:

Country:

Office_phone:

Research:

Home_address:

Home_phone: 
Fax:

E_mail_address:

Other:

The fields can be specified in any order. The subject line of your message is ignored. All fields are entered into the database as characters, so spaces can be used for readability. All fields (except first_name, last_name, and middle_name) can be multiple lines. A multiple-line field ends when the the next keyword (e.g. "Country:") is found. Place a $<$ return > character at the end of each line. In the rare exception that your first-name and last-name combination is not unique, send mail to "nanet@na-net.ornl.gov". We will manually insert your name into the white-pages despite the duplication. This should not cause any problems for people querying the white-pages database because it is set up to return information on ALL people with a given last name, first name, or combination. A message will be sent back to you confirming the operation was successful. See Appendix $B$ for an example of joining the white-pages.

3). Removing your White-pages entry - To remove y'our entry from the NA-NET whitepages database send mail to "na.remove-wp@na-net.ornl.gov". In the message body specify the following two fields.

Last_name:

First_name:

The values can be specified in any order. Again the subject line of your message is ignored. For security purposes, a confirmation message will be sent to both the address requesting the removal and also to the address listed in the white-pages database. See Appendix B for an example of removing your entry.

4). Changing fieids - To change the value of a field or to add a new field, send mail to "na.change-wp@na-net.ornl.gov". In the message body specify the following two fields plus the fields to be added or changed.

Last_name:

First_name:

The values can be specified in any order. Again the sub,$_{i}$. ct line oi your mess...ge is ignored. You cannot change your name. If you wish to do so, first remove your entry and the rejoin with the new name. If you wish to clear the value of a field, simply include the field with no value. A message will be sent back to you confirming the operation was successful. See Appendix B for an example on how to change or add a field. 


\section{THE UNDERLYING SOFTWARE}

The following section discusses the NA-NET software from an implementation perspective.

The NA-NET system was developed to run on a UNIX system. In crder to install this software superuser privileges were required to modify the following three files. The pathnames of these files may vary from one version of UNIX to another.

$$
\begin{aligned}
& \text { /usr/lib/aliases } \\
& \text { /etc/sendmail.cf } \\
& \text { /usr/lib/crontab }
\end{aligned}
$$

We begin, in Sections 3.1 and 3.2, with a discussion of how the incoming mail is caught and processed. Sections 3.3 and 3.4 describe the $\log$ files and the daily usage report. Together these two features keep the NA-NET administrators informed daily on which facilities are being used the most. Next in Sections 3.5 and 3.6 we look at how the weekly digest is sent and the how bad addresses are removed. Section 3.7 takes a closer look at the format of the white-pages database file. Finally, in Section 3.8 we describe how you can obtain your own copy of the NA-NET software.

\subsection{Catching and Storing Incoming Mail}

The first step in writing the NA-NET was getting all mail to be delivered to one location for processing. This was accomplished by adding the following two lines to the sendmail configuration file ("sendmail.cf").

1. Rna.St $\$$ \#namailer $\$: \$ 1$

2. Mnamailer, $P=/$ usr $/ \mathrm{cfs} 1 /$ nanet $/$ namailer, $F=$ lsDFMe, $A=$ namailer $\$ u$

The first line is a rewriting rule. As the incoming address is being parsed, sendmail scans through a set of rewriting rules looking for a match on the left hand side (LHS) of the rule. In this case it catches all mail beginning with "na." which is followed by one or more tokens. The symbol " $\$+$ " indicates - "match one or moze tokens." The symbol " $\$ \#$ " on the right hand side (RHS) of this rule causes evaluation of the ruleset to terminate immediately. It signals to sendmail that the address has been completely resolved.

The second line above defines the "namailer" and the arguments to pass to it. Below are listed the arguments and a short explanation. 


\begin{tabular}{|c|c|}
\hline $\mathrm{P}=/ \mathrm{usr} / \mathrm{cfs} 1 /$ nanet $/$ namailer & The path name of the mailer. \\
\hline$F=l s D F M E$ & $\begin{array}{l}\text { Flags } \\
\text { l - this maller is local } \\
\text { s - strip quote characters off } \\
\text { D - This mailer wants a "Date:" header line } \\
\text { F - This mailer wants a "From:" header line } \\
\text { M - This mailer wants a "Messge-Id:" header line } \\
\text { E - Escape lines beginning with "From" in the } \\
\text { message with a '>' sign. }\end{array}$ \\
\hline$A=$ namailer & $\begin{array}{l}\text { The argument vector to pass to this mailer. } \\
\text { In this case it is the word "namailer" }\end{array}$ \\
\hline$\$ u$ & The words containing the name of the receiving user. \\
\hline
\end{tabular}

For more information on the sendmail configuration file see $[1,2]$.

As shown below the namailer reads from standard input and temporarily appends the incoming message (header and body) to the file "incoming.mail".

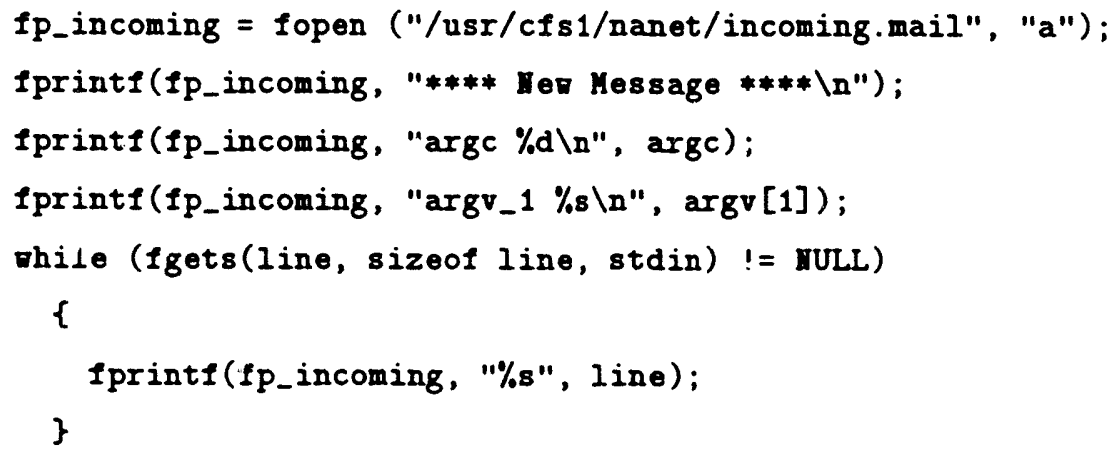

The recipient of the message cannot always be determined from the "To:" field of the header, because the message might be addressed to more than one person. Therefore the recipient of the message is passed as the final argument to the mailer and is stored as well as the message itself. The sender of the message however is read from the "From:" field of the header.

\subsection{Processing the Incoming Mail}

The rext step is to process the incoming mail. To do this we added the following line to a cron file

$$
0,5,10,15,20,25,30,35,40,45,50,55 * * * * / \text { usr/cfs1/nanet/nanet_daemon }
$$

The crontab file consists of lines of six fields each. The first 5 fields specify the time (minute, hour, day-of-the-month, month, year, and day of the week). The 6 th field specifies a command that should be executed. In our case the command is actually an executable file called 
"nanet_daemon" The asterisk indicates all legal values. So every 5 minutes the file nanet_daemon is executed.

The program "nanet_daemon" takes the first message from "incoming.mail" and temporarily stores it into "next_mail.message". After it has been stored, the following call is made.

$$
\text { system("/usr/cfs1/nanet/send_mail") }
$$

This program first examines the recipient $(\operatorname{argv}[1])$ to see if it is one of the following:

sendlist
help
join
remove
change
digest
whois
join-wp
change-wp
remove-wp

If the recipient is not one $n f$ the above, then it is assumed that the message is intended for an individual. Figure 2 show the format of the NA-NET files. When a message is destined for an individual, the file "nanet_names.na" is first searched. This file is sorted by the users "na" key. The "na" key is usually the users last name. An exception occurs when more than one person has the same last name. In this case the users "na" key is formed by prepending their first initial to their last name. In the example in figure 2, there are two Smith's (David and John) As shown David's key is dsmith whereas John's key is jsmith. So if mail was sent to "na.dsmith@nanet.ornl.gov" the mail wou!d be forwarded to "smith@cs.utk.edu" Likewise, if mi il was sent to "na.jsmith@na-net.ornl.gov" the mail would be forwarded to "smith@math.utk.edu"

If the recipient is not found in the "nanet_names.na" hile then a search is performed on the "nanet_names.last" file. For example if someone sends mail to "na.smith@na-net.ornl.gov", the following message would be returned.

Ambiguous key: try one of the following.

smith, david = na.dsmith

smith, john = na.jsmith

This message informs the sender that there are two members with the lastname smith and also gives their NA-NET address.

The following diagram shows the NANET file hierarchy. 


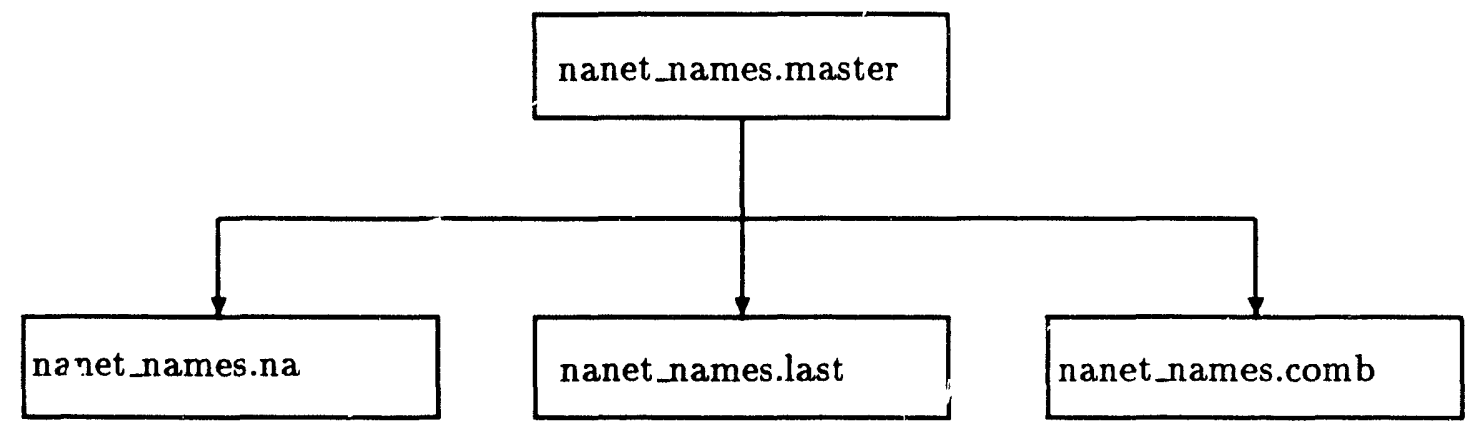

Figure 1: NA-NET files

nanet_names.master

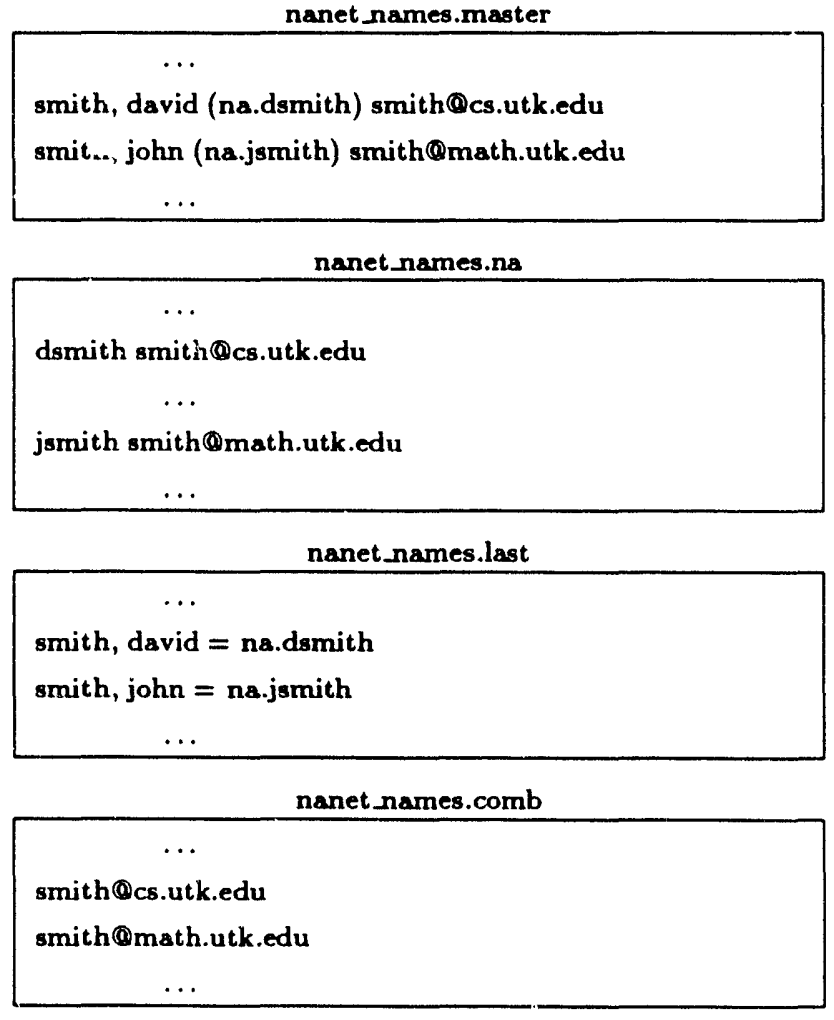

Figure 2: : ormat of NA-NET files

Upon a careful examination of the NA-NET source code you will find that the variable WHOTO determines where the message will actually be sent to. The 3 possible options are:

1. Send a message back to the user - This condition arises in the following situations:

- Anytime mail is sent to - "na.help@na-net.ornl.gov"

- Anytime mail is sent to - "na.sendlist@na-net.ornl.gov"

- Anytime mail is sent to - "na.digest@na-net.ornl.gov" 
- Anytime mail is sent to - "na.whois@na-net.ornl.gov"

- Mail sent to a nonexistent NA-NET name will result in an error message being returned.

- Mail sent to a non-unique NA-NET name also will result in an error message being returned to the sender.

2. Forward the message - All incoming mail to valid individuals is simply forwarded.

3. Send mail to all addresses in the file "addresses.txt" - This third condition arises when: changing an e-mail address, changing a field in the white-pages, or removing a member from either the $\mathrm{N} A_{2}$-NET or white-pages. For example if someone changed their e-mail address the following 3 locations would all receive a confirmation - assuming the 3 addresses were different.

- The add ss requesting the change

- The new address

- The old address

Shown below is a message send to "na.brosener@na-net.ornl.gov" from "rosener@cs.utk.edu" This example illustrates how messages appear to have come from the sender, even though it was forwarded though the NA-NET.

$>$ From rosenereUTiKX 1 . utk.edu Hed Jun $1917: 42: 261991$

Return-Path: 〈rosenereuTKUX1.utk.edu〉

Received: from surfer.EPM.ORML.GOV by CS.UTK.EDU vith SHTP (5.61t+/2.5.1s-UTK)

id 1101526; Hed, 19 Jun 91 17:42:22 -0400

Received: by surfer.EPM.ORII.GOV $(5.61 / 1.34)$

id A114525; Wed, 19 Jun 91 16:0€:09 -0400

Received: from UTKUX1.UTK.EDU by surfer.EPM.ORIL.GOV (5.61/1.34)

id 1114515; Wed, 19 Jun 91 16:05:08 -0400

Received: by UTKUX1.utk.edu (5.57/U1trix2.4-C)

id 1128369; Wed, 19 Jun 91 16:04:34 EDT

Date: Wed, 19 Jun 91 16:04:34 EDT

From: rosenerQutkux1.utk.edu (Bill Rosener)

Message-Id: 〈9106192004.1A28369QUTKUX1 .utk.edu>

To: na.brusenerosurfer.EPH. ORML.GOV

Subject : test

Status: $\mathbf{R}$ 


\subsection{Log and Debug Files}

To help with record keeping the file "log.txt" records all requests made on any given day. At midnight this file is appended to the yearly log file. Because of the large size of the yearly log file, we also maintain log files for the past 7 days for convenience. Shown below is a portion of a $\log$ file.

1991619 14:11 From dongarra@cs.utk.edu Wed Jun 19 14:10:39 1991

To: na.help@surfer.EPM.ORNL.GOV

1991619 14:12 From dongarra@cs.utk.edu Wed Jun 19 14:10:58 1991

To: na.brosener@surfer.EPM.ORNL.GOV

1991619 14:12 From dongarra@cs.utk.edu Wed Jun 19 14:11:08 1991

To: na.join-wp@surfer.EPM.ORNL.GOV

To help with the development of the NA-NET and also to help solve user problems, we also maintain one weeks worth of debug files. For example members sometimes have trouble when changing their e-mail addresses. To change ones e-mail address, a user must send a message to the NA-NET containing their first name, last name, and new e-mail address. Occassionally, they use a different form of their first name. (For example, "William" instead of "Bill") Now the administrators of the NA-NET can examine the debug file when answering questions, and can determine that the user specified the wrong first name.

\subsection{Daily Usage Report}

To let the NANET administrators know which facilities are being used the most, a Usage Report is sent out every night. This brief report indicates how many mail messages were sent to each feature and how many mail message are currently in the collect file. Mail to na.digest is stored in the collect file. Below is a typical NA-NET usage report.

\section{RA-MET usage}

91 mail message(s) vere sent to the MA-BET on: Jun 13

Analysis of mail messages sent today:

To na.sendlist $=2$

To na.help $\quad=7$ 


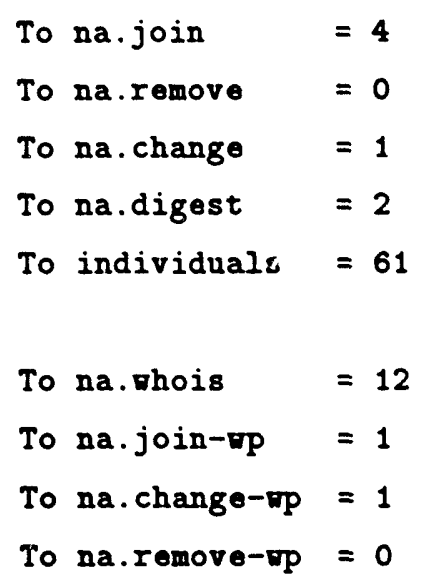

To send this nightly mail message, the following line has been added to the cron file. This file requires superuser privileges to modify.

$5923 * * *$ /usr/cfs1/nanet/CRON/daily_mail

This line indicates the program daily_mail should be executed at 1 minute before midnight every day. This program analyzes the current day's log file (i.e. "log.txt") and constructs a usage report in the file "usage.txt". As shown below the file "usage.txt" is then opened as standard input and the system command execl is invoked.

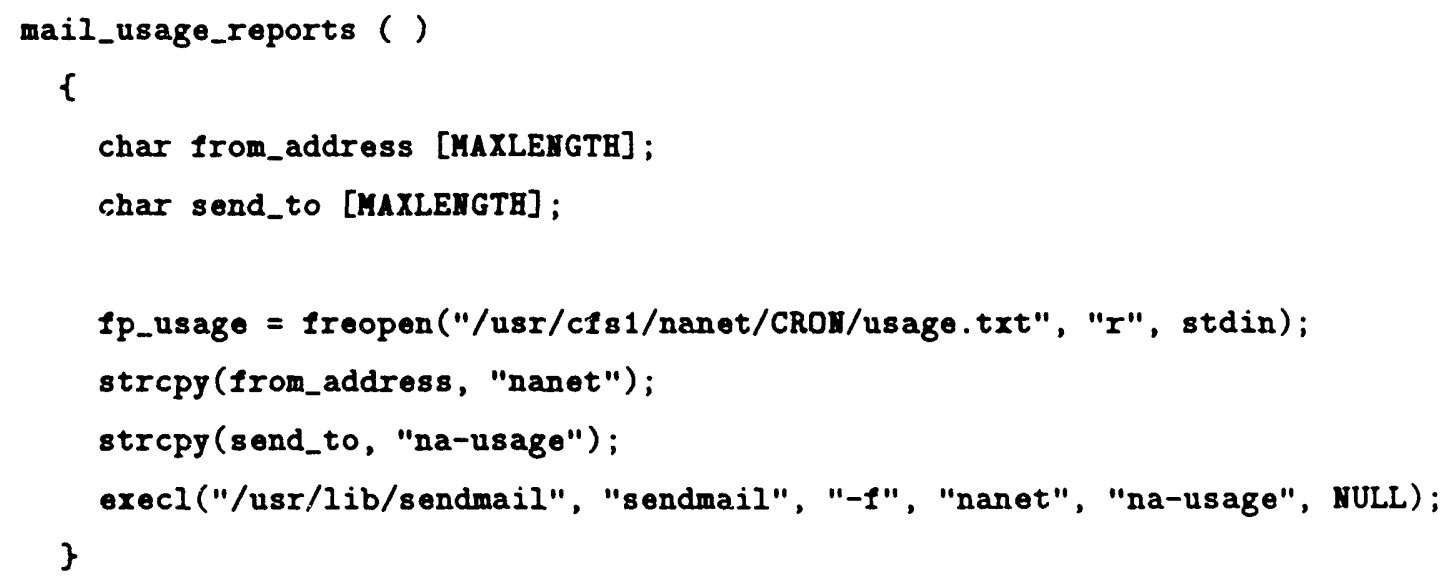

Below is a brief description of the arguments to the system call execl. 
"/usr/lib/sendmail" - is the pathname for the message transfer agent.

"sendmail" - the name of the program

"-f" - sets the name of the "from" person (i.e. the sender of the mail).

"nanet" - who the mail is from

"na-usage" - recipient of mail

NULL - a null pointer is used to terminate the variable number of arguments. As shown above the recipient of the usage report is "na-usage". This address is included in the alias file.

The file "/usr/lib/aliases" contains the following

na-usage: :include:/usr/cfs1/nanet/CRON/usage.addresses

owner-na-usage: nanet

In sendmail this technique is called inclusion. Any mail send to na-usage will read the file "usage.addresse" and send the mail to all users listed in this file. Inclusion allows a mailing list to be changed without the interaction of a system administrator, because on most systems the alias file is protected. For more information on this technique see [1]. (section 3.3.3)

The file "/usr/cfs1/nanet/CRON/usage.addresses" currently contains the following addresses:

dongarra@cs.utk.edu

golub@Cholesky.Stanforu.EDU

moler@surfer.epm.ornl.gov

rosener@cs.utk.edu

In addition to sending the usage report, the program daily_mail also copies the log files and debug files as shown below. These files can be very helpful while trying to figure out problems. system ("cp `nanet/log5 -nanet/log6");

system ("cp nanet/log4 nanet/log5"); system ("cp nanet/log3 nanet/log4");

system ("cp -nanet/log2 -nanet/log3"); system ("cp $\sim$ nanet/log1 nanet/log2"); system ("cp nanet/log.txt $\sim$ nanet/log1"); 


\subsection{Sending the Digest}

Approximately once a week the Editor of the NA-NET News Digest will go over the messages that have queued up, pick out the ones that are thought to be of general interest to the numerical analysis and mathematical software community, combine them in a News Digest format, and mail the Digest to everyone on the mailing list. The digest is sent from the account "nacomb" unlike the rest of the NA-NET which resides in the account "nanet." One reason of this approach is that the mail to this account does not need to be carefully read since it only contains bounced digest mail. Whereas if the digest was sent from a personal account then that person would have to carefully sort through their mail removing all bounced digest messages. A second reason for of a separate account is that it ensures that the combined list is not being updated while the digest is being sent. For whenever a user joins the NA-NET or changes their e-mail address this file is updated. Thus as shown below, the first step in sending the digest is to copy an updated version of the combined list to the "nacomb" account.

1. Execute the following command.

cp nanet/nanet_names.comb nacomb/nanet_names.comb

This ensures that the list is up-todate.

2. Store last weeks' returned mail so that bad addresses can be removed.

$m v /$ usr/spool/mail/nacomb filename.txt

3. Place the message you wish to send in the file "message.txt"

4. Execute the program send_digest.

$>$ send_digest

This program sends out approximately one mail message every 3 seconds. Currently, there are about 2000 members in the NA-NET. So it will take about 2 hours to complete. It is probably a good idea to check that the last mail message sent is also the last address in the file nanet_names.comb.

\subsection{Removal of Bad Addresses}

When sending the digest to the cumbined list, some of the message sent may bounce. The following is a partial list of the reasons that cause messages to bounce.

- The user submits an invalid address when using the auto-join or auto-address change facilities of the NA-NET.

- A hast is down. 
- A user's account has expired. The users account was maybe either temporary or they moved to a new address.

- Problems in remote mailing lists.

The administrators of the NA-NET have decided upon the following policy concerning bad addresses. If an address fails 3 weeks in a row, that address will be removed from the the masier database file ("nanet_names.master"). To remove bad addresses, the following steps are taken approximately every month.

1. parse_bad_mail file_namei

mv Bad.Addresses Bad1

parse_bad_mail file_name2

mv Bad.Addresses Bad2

parse_bad_mail file_names

mv Bad.Addresses Bad 3

2. sort Bad1 > Bad11

sort Bad2 > Bad22

sort Bad9 > Bad99

3. comm -12 Bad11 Bad22 > Bad12

comm -12 Bad12 Bad39> Allbad

4. Remove the addresses in "Allbad" from the file "nanet_names.master"

First, the program "parse_bad_mail" goes through a file of returned mail and extracts the bad addresses from the "Apparently-To:" field. The addresses are then sorted. Next the command "comm" is invoked. This selects those lines that are common to the two sorted files. Finally, the the bad addresses are removed.

\subsection{NA-NET White-pages}

Below is a short description of the format of the white-pages database file. The entries are stored in the file "whitepages.database." This file is a plain ASCII file. However, because users can include spaces in all fields (except first_name, last_name, and middle_name), a special character must be used to denote the end of a field. The special character $\wedge \quad M$ has been choosen to denote the end of a field. The character $\wedge \mathrm{A}$ is used to denote the end of line when multiple lines are used for one field. Shown below is a line from the file "whitepages.database". 
Dongarra-MJack-MJ. -M-MUniversity of Tennessee and Dak Ridge National Laboratory-MDept. of Computer Science; 107 Ayres Hall-MKnoxville, TN 37996-1301-MUSA-M(615) 974-8295-M Numerical Linear Algebra^AParallel Processing-ASoftrare Tools-A`M107 Claymore Ln; Dak Ridge, TK 37830-M(615) 481-8295 M(615) 974-8296-Mdongarraecs.utk.edu-MFeel free to call me from 8 an until $11 \mathrm{pm}$. -MJun $1991^{-M}$

The research field of Jack Dongarra is the only multiple-line field. This example also illustrates how a blank field is represented. In this example the field "Other-name:" has not been specified. This is stored in the database file as two M's. (See the first line of the sample entry.) The program "print-wp.c" has been written to allow the NA-NET administrators to examine this somewhat encrypted file. Shown below is the output from this program using the example above.

Last Name: Dongarra

First Name: Jack

Middle Name: J.

Affiliation: University of Tennessee and Oak Ridge National Laboratory

Office Address: Dept. of Computer Science; 107 Ayres Hall

City State Zip: Knoxville, TN 37996-1301

Country: USA

Office Phone: (615) 974-8295

Research: Numerical Linear Algebra $<M U L T I P L E-L I N E S>$

Parallel Procassing

Software Tools

Home address: 107 Claymore Ln; Oak Ridge, TN 37830

Home phone: (615) 481-8295

Fax: (615) 974-8296

E-mail address: dongarra@cs.utk.edu

Other: Feel free to call me from 8 am until $11 \mathrm{pm}$.

Correct as of: Jun 1991

The following two commands can be helpful when examing the white-pages database file.

$$
\text { print-wp } \mid \text { more } \quad \text { print-wp }>\text { filename }
$$

\subsection{How to Obtain the NA-NET Software}

The NA-NET software can be obtained through netlib by sending the message, send na-net from misc to netlib@ornl.gov 
Or send postal mail to:

Jack Dongarra

University of Tennessee

Dept. of Computer Science

107 Ayres Hall

Knoxville, TN 37996-1301

dongarra@cs.utk.edu

(615) 974-8295

\section{Appendix A}

Below are some real examples to give you an idea of how the /small NA-NET works.

1. For example, to mail to Gene Golub.

mail to: na.golub@na-net.ornl.gov

2. Mail sent to a nonexistent NA-NET name. For example, mail sent to: na.abcde@na-net.ornl.gov

will result in the following message being returned to you.

NA-NET key not found. Message returned.

3. Mail sent to a non-unique NA-NET name. For example,

mail sent to: na.fox@na-net.ornl.gov

will result in the following message being returned to you.

Ambiguous key: try one of the following

fox, david = na.dfox

fox, phyl = na.pfox

fox, $x=$ na.cfox 
4. An example of how Gene Golub would join the NA-NET.

mail na.join@na-net.ornl.gov

Subject: anything

Lastname: golub

Firstname: gene

E-mail: golub@patience.stanford.edu

5. An example of how Mike Foobar would remove his membership in the NA-NET.

mail na.remove@na-net.ornl.gov

Subject: anything

Lastname: foobar

Firstname: mike

key: foobar

6. An example of how Mike Fox would change his e-mail address.

mailna.change@na-net.ornl.gov

Subject: anything

Lastname: fox

Firstname: mike

New-address: mfox@new.address

key: $m$ fox

\section{Appendix B}

Below are some real examples to give you an idea of how the white-pages works.

1. For example, to find out more about Bill Rosener. The software has been written to understand many different forms. The following ar some of the acceptable forms.

mail to: na.whois@na-net.ornl.gov

Subject: "blank"

Bill Rosener

OR

mail to: na.whois@na-net.ornl.gov

Subject: "blank" 
Rosener Bill

OR

mail to: na.whois@na-net.ornl.gov

Subject: "blank"

whois Rosener Bill

OR

mail to: na.whois@na-net.ornl.gov

Subject: bill rosener

NULL body

OR

mail to: na.whois@na-net.ornl.gov

Subject: whois bill rosener

NULL body

OR

mail to: na.whois@na-net.ornl.gov

Subject: "blank"

last-name: rosener

first-name: bill

A message similar to the following will then be returned. 
Last Name: Rosener

First Name: Bill

Middle Name: J.

Affiliation: University of Tennessee

Office Address: Dept. of Computer Science; 107 Ayres Hall

City State Zip: Knoxville, TN 37996-1301

Country: U.S.A.

Office Phone: (615) 974-3647

Research: Highly-interactive, direct manipulation,

3D graphical interfaces.

Home Address: 1403 White Ave; Knoxville TN, 37910́

Fax: 615-974-8296

E-mail Address: rosener@cs.utk.edu

Other: graduate student

Correct as of: Jun 1991

2. For example, to find out more information on all people whose last name is "smith".

mail to: na.whois@na-net.ornl.gov

Subject: "blank"

smith

3. For example, to find out more information on all people who are interested in "parallel". This does a string comparison on all fields other than the name fields searching for the pattern "parallel".

mail to: na.whois@na-net.ornl.gov

Subject: "blank"

Keyword: parallel

4. For example, to find out more information on all people who live in "Knoxville". This does a string comparison on all fields other than the name fields searching for the pattern "Knoxville".

mail to: na.whois@na-net.ornl.gov

Subject: "blank"

Keyword: Knoxville 
5. An example of how Bill Rosener would join the white-pages.

mail na.join-wp@na-net.ornl.gov

Subject: anything

Last_name: Rosener

First_name: Bill

Middle_name: J.

Affiliation: University of Tennessee

Office_address: Dept. of Computer Science; 107 Ayres Hall

City_state_zip: Knoxville, TN 37996-1301

Country: U.S.A.

Office_phone: (615) 974-3647

Research: Highly-interactive, direct manipulation, < return >

3D graphical interfaces.

Home_address: 1403 White Ave; Knoxville 'TN, 37916

E_mailaddress: rosener@cs.utk.edu

Other: graduate student

Note: That the optional fields "Fax", "Home_phone", and "Other_name" were not given, so people querying Bill Rosener will not find this information.

6. An example of how Mike Foobar would remove his entry from the white-pages.

mail na.remove-wp@na-net.ornl.gov

Subject: anything

Last_name: foobar

First_name: mike

7. An example of how Mike Fox would change his E-mail address and Fax number while also clearing his Home Phone number in the white-pages.

mail na.change-wp@na-net.ornl.gov

Subject: anything

Last_name: fox

First_name: mike

E_mail_address: fox@new.address

Home_phone:

Fax: (764) 285-4239 


\section{References}

[1] Eric Allman. Sendmail Installation and Operation Guide Version 5.11. For Sendmail Version 5.61. Britton-Lee, Inc. July 1983.

[2] Eric Allman. Sendmail - An Internetwork Mail Router Britton-Lee, Inc. July 1983.

[3] Jack Dongarra and Eric Grosse. Distribution of Mathematical Software Via Electronic Mail Communications of the ACM, Volume 30 (Number 5), May 1987.

[4] Mark Kent. ETH Ezdgenossische Technische Hochschle Zurich. The Numerical Analysis Net. January 1988. 
ORNL/TM-11986

\section{INTERNAL DISTRIBUTION}

$\begin{aligned} \text { 1. } & \text { B. R. Appleton } \\ 2-3 . & \text { T. S. Darland } \\ 4 . & \text { E. F. D' Azevedo } \\ 5 . & \text { J. M. Donato } \\ 6-10 . & \text { J. J. Dongarra } \\ 11 . & \text { T. H. Dunigan } \\ 12 . & \text { G. A. Geist } \\ 13 . & \text { M. R. Leuze } \\ 14 . & \text { E. G. Ng } \\ 15 . & \text { C. E. Oliver } \\ 16 . & \text { B. W. Peyton } \\ \text { 17-21. } & \text { S. A. Raby } \\ 22 . & \text { C. H. Romine }\end{aligned}$

$\begin{aligned} & 23 . \text { T. H. Rowan } \\ & 24-28 . \text { R. F. Sincovec } \\ & 29-33 . \text { R. C. Ward } \\ & 34 . \text { P. H. Worley } \\ & 35 . \text { A. Zucker } \\ & 36 . \text { Central Research Library } \\ & 37 . \text { ORNL Patent Office } \\ & 38 . \text { K-25 Applied } \\ & 39 . \text { Technology Library } \\ & 39.12 \text { Technical Library } \\ & 40 . \text { Laboratory Records - RC } \\ & 41-42 . \text { Laboratory Records Department }\end{aligned}$

\section{EXTERNAL DISTRIBUTION}

43. Cleve Ashcraft, Boeing Computer Services, P.O. Box 24346, M/S 7L-21, Seattle, WA 98124-0346

44. Robert G. Babb, Department of Computer Science and Engineering, Oregon Graduate Institute, 19600 N.W. Walker Rd., Beaverton, OR 97006

45. David H. Bailey, NASA Ames Research Center, Mail Stop 258-5, Moffett Field, CA 94035

46. Jesse L. Barlow, Department of Computer Science, Pennsylvania State University, University Park, PA 16802

47. Edward H. Barsis, Computer Science and Mathematics, P. O. Box 5800, Sandia National Laboratories, Albuquerque, NM 87185

48. Eric Barszcz, NASA Ames Research Center, MS T045-1, Moffett Field, CA 94035

49. Rojert E. Benner, Parallel Processing Division 1413, Sandia National Laboratories, P. O. Box 5800, Albuquerque, NM 87185

50. Donna Bergmark, Comell Theory Center, Engineering and Theory Center Building, Ithaca, NY 14853-3901

51. Chris Bischof, Mathematics id Computer Science Division, Argonne National Laboratory, 9700 South Cass Ave., Argonne, IL 60439

52. Ake Bjorck, Department of Mathematics, Linkoping University, S-581 83 Linkoping, Sweden 
53. Jean R. S. Blair, Department of Computer Science, Ayres Hall, University of Tennessee, Knoxville, TN 37996-1301

54. Daniel Boley, Department of Computer Science, University of Minnesota, 200 Union St. S.E. Rm.4-192 Minneapolis, MN 55455

55. Roger W. Brockett (EPMD Advisory Committee), Wang Professor of Electrical Engineering and Computer Science, Division of Applied Sciences, Harvard University, Cambridge, MA 02138

56. James C. Browne, Department of Computer Sciences, University of Texas, Austin, TX 78712

57. Bill L. Buzbee, Scientific Computing Division, National Center for Atmospheric Research, P.O. Box 3000, Boulder, CO 80307

58. Donald A. Calahan, Department of Electrical and Computer Engineering, University of Michigan, Ann Arbor, MI 48109

59. John Cavallini, Office of Scientific Computing, Office of Energy Research, ER-7, Germantown Building, U.S. Department of Energy, Washington, DC 20545

60. Ian Cavers, Department of Computer Science, University of British Columbia, Vancouver, British Columbia V6T 1W5, Canada

61. Tony Chan, Department of Mathematics, University of California, Los Angeles, 405 Hilgard Ave., Los Angeles, CA 90024

62. Jagdish Chandra, Army Research Office, P.O. Box 12211, Research Triangle Park, NC 27709

63. Eleanor Chu, Department of Computer Science, University of Waterlon, Waterloo, Ontario, Canada N2L 3G1

64. Melvyn Ciment, National Science Foundation, 1800 G Street N.W., Washington, DC 20550

65. Thomas Coleman, Department of Computer Science, Comell University, Ithaca, NY 14853

66. Paul Concus, Mathematics and Computing, Lawrence Berkeley Laboratory, Berkeley, CA 94720

67. Jane K. Cullum, IBM T. J. Watson Research Center, P.O. Box 218, Yorktown Heights, NY 10598

68. George Cybenko, Center for Supercomputing Research and Development, University of Illinois, 104 S. Wright St., Urbana, IL 61801-2932

69. George J. Davis, Department of Mathematics, Georgia State University, Atlanta, GA 30303

70. John J. Dorning, (EPMD Advisory Committee), Department of Nuclear Engineering Physics, Thomton Hall, McCormack Rd., University of Virginia, Charlottesville, VA 22901 
71. Iain S Duff, Atlas Centre, Rutherford Appleton Laboratory, Chilton, Oxon OX11 OQX England

72. Patricia Eberlein, Department of Computer Science, SUNY at Buffalo, Buffalo, NY 14260

73. Stanley Eisenstat, Department of Computer Science, Yale University, P.O. Box 2158 Yale Station, New Haven, CT 06520

74. Lars Elden, vepartment of Mathematics, Linkoping University, 58183 Linkoping, Sweden

75. Howard C. Elman, Computer Science Department, University of Maryland, College Park, MD 20742

76. Albert M. Erisman, Boeing Computer Services, P.O. Box 24346, M/S TL-21, Seattle, WA 98124-0346

77. Ian Foster, Mathematics and Computer Science Division, Argonne National Laboratory, 9700 South Cass Ave., Argonne, IL 60439

78. Geoffrey C. Fox, Booth Computing Center 158-79, Califomia Institute of Technology, Pasadena, CA 91125

79. Paul O. Frederickson, NASA Ames Research Center, RIACS, M/S T045-1 Moffett Field, CA 94035

80. Fred N. Fritsch, Computing \& Mathematics Research Division, Lawrence Livermore National Laboratory, P. O. Box 808, L-316 Livermore, CA 94550

81. Robert E. Funderlic, Department of Computer Science, North Carolina State University, Raleigh, NC 27650

82. Dennis B. Gannon, Computer Science Department, Indiana University, Bloomington, IN 47405

83. David M. Gay, Bell Laboratories, 600 Mountain Ave., Murray Hill, NJ 07974

84. C. William Gear, Computer Science Department, University of Illinois, Urbana, IL 61801

85. W. Morven Gentleman, Division of Electrical Engineering, National Research Council, Building M-50, Room 344, Montreal Rd., Ottawa, Ontario, Canada K1 A OR8

86. J. Alan George, Vice President, Academic and Provost, Needles Hall, University of Waterloo, Waterloo, Ontario, Canada N2L 3G1

87. John R. Gilbert, Xerox Palo Alto Research Center, 3333 Coyote Hill Rd., Palo Alto, CA 94304

88. Gene H. Golub, Department of Computer Science, Stanford University, Stanford, CA 94305

89. Joseph F. Grcar, Division 8331, Sandia National Laboratories, Livermore, CA 94550

90. Sven Hammarling, Numerical Algorithms Group Ltd. Wilkinson House, Jordan Hill Road Oxford OX2 8DR, United Kingdom 
91. Per Christian Hansen, UNI*C Lyngby, Building 305, Technical University of Denmark, DK-2800 Lyngby, Denmark

92. Richard Hanson, IMSL Inc., 2500 Park West Tower One, 2500 City West Blvd., Houston, TX 77042-3020

93. Michael T. Heath, National Center for Supercomputing Applications, 4157 Beckman Institute, University of Illinois, 405 North Mathews Avenue, Urbana, IL 61801-2300

94. Don E. Heller, Physics and Computer Science Department, Shell Development Co., P.O. Box 481, Houston, TX 77001

95. Nicholas J. Higham, Department of Mathematics, University of Manchester, Grt Manchester, M13 9PL, England

96. Charles J. Holland, Air Force Office of Scientific Research, Building 410, Bolling Air Force Base, Washington, DC 20332

97. Robert E. Huddleston, Computation Department, Lawrence Livermore National Laboratory, P.O. Box 808, Livermore, CA 94550

98. Ilse Ipsen, Department of Computer Science, Yale University, P.O. Box 2158 Yale Station, New Haven, CT 06520

99. Elizabeth Jessup, University of Colorado, Department of Computer Science, Boulder, CO 80309-0430

100. Lennart Johnsson, Thinking Machines Inc., 245 First St., Cambridge, MA 02142 1214

101. Harry Jordan, Department of Electrical and Computer Engineering, University of Colorado, Boulder, CO 80309

102. Bo Kagstrom, Institute of Information Processing, University of Umea, 5-901 87 Umea, Sweden

103. Malvin H. Kalos, Comell Theory Center, Engineering and Theory Center Building, Comell University, Ithaca, NY 14853-3901

104. Hans Kaper, Mathematics and Computer Science Division, Argonne National Laboratory, 9700 South Cass Ave., Argonne, IL 60439

105. Robert J. Kee, Applied Mathematics Division 8331, Sandia National Laboratories, Livermore, CA 94550

106. Kenneth Kennedy, Department of Computer Science, Rice University, P.O. Box 1892, Houston, TX 77005

107. Thomas Kitchens, Department of Energy, Scientific Computing Staff, Office of Energy Research, ER-7, Office G-236 Germantown, Washington, DC 20585

108. Richard Lau, Code $1111 \mathrm{MA}, 800 \mathrm{~N}$. Quincy Street, Boston Tower, 1 Arlington, VA 22217-5000

109. Alan J. Laub, Departmerit of Electrical and Computer Engineering, University of Califomia, Santa Barbara, CA 93106 
110. Robert L. Launer, Army Research Office, P.O. Box 12211, Research Triangle Park, North Carolina 27709

111. Charles Lawson, MS 301-490, Jet Propulsion Laboratory, 4800 Oak Grove Dr., Pasadena, CA 91109

112. Peter D. Lax, Courant Institute of Mathematical Sciences, New York University, 251 Mercer St., New York, NY 10012

113. James E. Leiss (EPMD Advisory Committee), Rt. 2, Box 142C, Broadway, VA 22815

114. John G. Lewis, Boeing Computer Services, P.O. Box 24346, M/S 7L-21, Seattle, WA 98124-0346

115. Jing Li, IMSL Inc., 2500 Park West Tower One, 2500 City West Blvd., Houston, TX 77042-3020

116. Joseph Liu, Department of Computer Science, York University, 4700 Keele St., North York, Ontario, Canada M3J 1P3

117. Franklin Luk, School of Electrical Engineering, Comell University, Ithaca, NY 14853

118. Thomas A. Manteuffel, Department of Mathematics, University of Colorado Denver, Denver, CO 80202

119. Peter Mayes, NAG Ltd., Wilkinson House, Jordan Hill Road, Oxford, OX2 8DR, United Kingdom

112. Paul C. Messira, Mail Code 158-79, Califomia Institute of Technology, 1201 E. Califomia Blvd. Pasadena, CA 91125

113. James McGraw, Lawrence Livermore National Laboratory, L-306, P.O. Box 808, Livermore, CA 94550

114. Cleve Moler, The Mathworks, 325 Linficld Place, Menlo Park, CA 94025

115. Neville Moray (EPMD Advisory Committee), Department of Mechanical and Industrial Engineering, University of Illinois, 1206 West Green Street, Urbana, IL 61801

116. Brent Morris, National Security Agency, Ft. George G. Meade, MD 20755

117. Dianne P. O'Leary, Computer Science Department, University of Maryland, College Park, MD 20742

118. James M. Ortega, Department of Applied Mathematics, Thomton Hall University of Virginia, Charlottesville, VA 22903

119. Chris Paige, Department of Computer Science, McGill University, 805 Sherbrooke St. W., Montreal, Quebec, Canada H3A 2K6

120. Roy P. Pargas, Department of Computer Science, Clemson University, Clemson, SC 29634-1906

121. Beresford N. Parlett, Department of Mathematics, University of Califomia, Berkeley, CA 94720 
122. Merrell Patrick, Department of Computer Science, Duke University, Durham, NC 27706

123. Rober J. Plemmons, Departments of Mathematics and Computer Science, North Carolina State University, Raleigh, NC 27650

124. Jesse Poore, Department of Computer Science, Ayres Hall, University of Tennessee, Knoxville, TN 37996-1301

125. Alex Pothen, Department of Compuier Science, Pennsylvania State University, University Park, PA 16802

126. Michael J. Quinn, Computer Science Department, Oregon State University, Corvallis, OR 97331

127. Giuseppe Radicati di Brozolo, IBM European Center for Scientific and Engineering Computing, 00147 Roma, via Giorgione 159, Italy

128. Noah Rhee, Department of Mathematics, University of Missouri-Kansas City, Kansas City, MO 64110-2499

129. John K. Reid, Numerical Analysis Group, Central Computing Department, Atlas Centre, Rutherford Appleton Laboratory, Didcot, Oxon OX11 0QX, England

130. Wemer C. Rheinboldt, Department of Mathematics and Statistics, University of Pittsburgh, Pittsburgh, PA 15260

131. John R. Rice, Computer Science Department, Purdue University, West Lafayette, IN 47907

132. Garry Rodrigue, Numerical Mathematics Group, Lawrence Livermore Laboratory, Livermore, CA 94550

133. Donald J. Rose, Department of Computer Science, Duke University, Durham, NC 27706

134-138. Bill Rosener, Computer Science Department, University of Tennessee, Knoxville, TN 37996-1301

139. Ahmed H. Sameh, Computer Science Department, University of nlinois, Urbana, IL 61801

140. Michael Saunders, Systems Optimization Laboratory, Operations Research Department, Stanford University, Stanford, CA 94305

141. Robert Schreiber, RIACS, Mail Stop 230-5, NASA Ames Research Center, Moffet Field, CA 94035

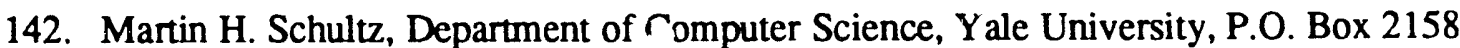
Yale Station, New Haven, CT 06520

143. David S. Scott, Intel Scientific Computers, 15201 N.W. Greenbrier Pkwy., Beaverton, OR 97006

144. Lawrence F. Shampine, Mathematics Department, Southern Methodist University, Dallas, TX 75275 
145. Kermit Sigmon, Department of Mathematics, University of Florida, Gainesville, FL 32611

146. Horst Simon, Mail Stop 258-5, NASA Ames Research Center, Moffett Field, CA 94035

147. Larry Snyder, Department of Computer Science and Engineering, FR-35, University of Washington, Seattle, WA 98195

148. Danny C. Sorensen, Department of Mathematical Sciences, Rice University, P. O. Box 1892, Houston, TX 77251

149. Rick Stevens, Mathematics and Computer Science Division, Argonne National Laboratory, 9700 South Cass Ave., Argonne, IL 60439

150. G. W. Stewart, Computer Science Department, University of Maryland, College Park, MD 20742

151. Quentin F. Stout, Department of Electrical and Computer Engineering, University of Michigan, Ann Arbor, Ml 48109

152. Daniel B. Szyld, Depanment of Computer Science, Duke University, Durham, NC 27706-2591

153. W.-P. Tang, Department of Computer Science, University of Waterloo, Waterloo, Ontario, Canada N2L 3G1

154. Michael Thomason, Department of Computer Science, Ayres Hall, University of Tennessee, Knoxville, TN 37996-1301

155. Bernard Tourancheau, LIP ENS-Lyon 69364 Lyon cedex 07, France

156. Charles Van Loan, Department of Computer Science, Comell University, Ithaca, NY 14853

157. James M. Varah, Centre for Integrated Computer Systems Research, University of British Columbia, Office 2053-2324 Main Mall, Vancouver, British Columbia V6T 1W5, Canada

158. Robert G. Voigt, ICASE, MS 132-C, NASA Langley Research Center, Hampton, VA 23665

159. Michael Vose, Department of Computer Science, Ayres Hall, University of Tennessee, Knoxville, TN 37996-1301

160. Phuong Vu, Cray Research Inc., 1408 Northland Dr., Mendota Heights, MN 55120

161. E. L. Wachspress, Department of Mathematics, University of Tennessee, Knoxville, TN 37996-1300

162. Daniel D. Warner, Department of Mathematical Sciences, O-104 Martin Hall, Clemson University, Clemson, SC 29631

163. D. S. Watkins, Department of Pure and Applied Mathematics, Washington State University, Pullman, WA 99164-2930 
164. Mary F. Wheeler (EPMD Advisory Committee), Rice University, Department of Mathematical Sciences, P.O. Box 1892, Houston, TX 77251

165. Andrew B. White, Computing Division, Los Alamos National Laboratory, Los Alamos, NM 87545

166. Michael Wolfe, Oregon Graduate Institute, 19600 N.W. von Neumann Dr., Beaverton, OR 97006

167. Margaret Wright, Bell Laboratories, 600 Mountain Ave., Murray Hill, NJ 07974

168. David Young, University of Texas, Center for Numerical Analysis, RLM 13.150, Austin, TX 78731

169. Office of Assistant Manager for Energy Research and Development, U.S. Department to Energy, Oak Ridge Operations Office, P.O. Box 2001, Oak Ridge, TN 37831-8600

170-179. Office of Scientific Technical Information, P.O. Box 62, Oak Ridge, TN 37831 

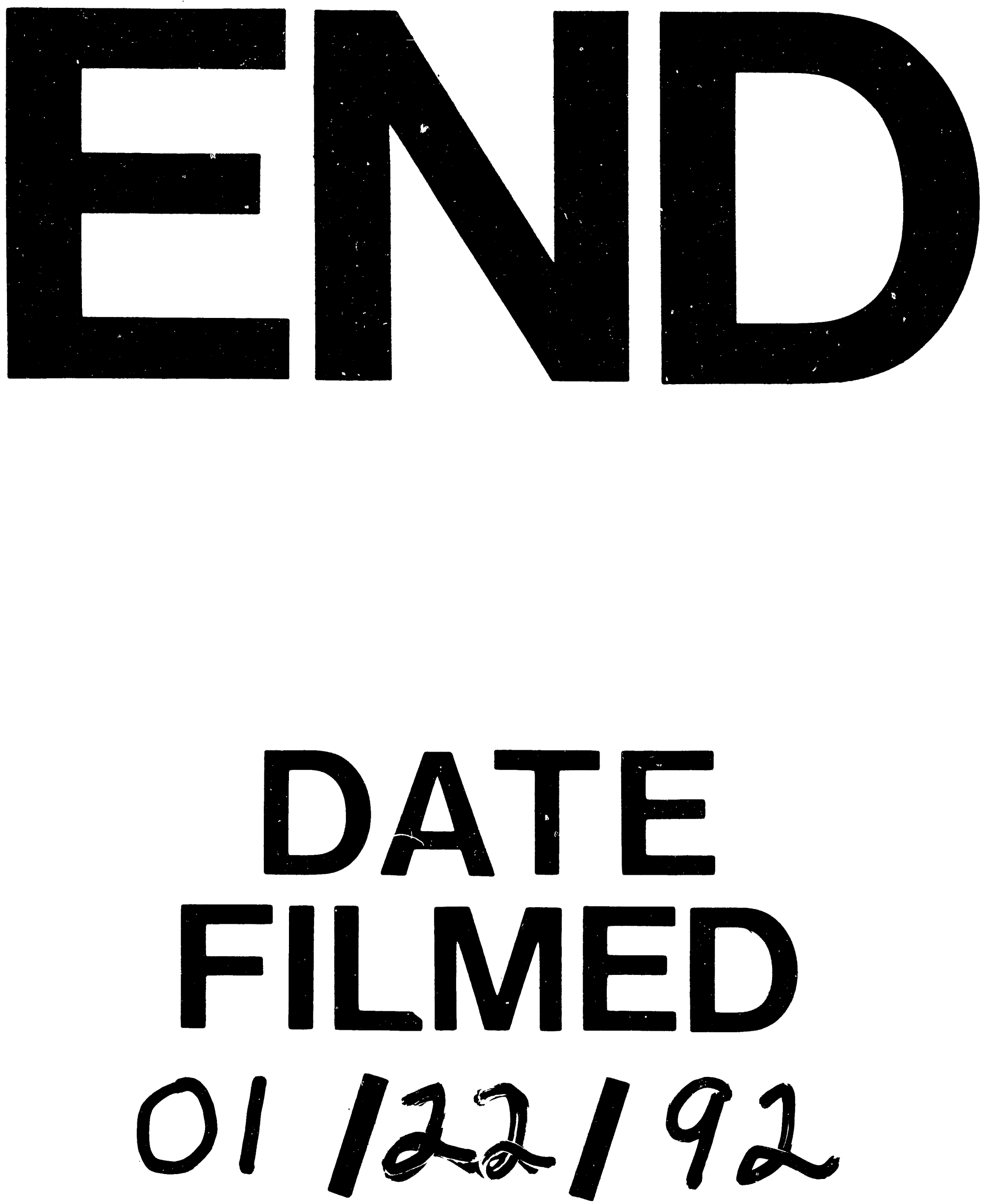
